\title{
Gambaran Keinginan Unmet Need terhadap Pelayanan KB di Kota Yogyakarta
}

\author{
Susiana Sariyati ${ }^{1}$, Hilmi Alfiana ${ }^{1}$ \\ ${ }^{1}$ Sekolah Tinggi IImu Kesehatan Alma Ata Yogyakarta \\ Jalan Ringroad Barat Daya No 1 Tamantirto, Kasihan, Bantul Yogyakarta
}

\begin{abstract}
Abstrak
Provinsi DIY merupakan salah satu provinsi di Indonesia yang mempunyai unmet need yang tinggi mencapai $13,69 \%$ pada tahun 2012. Penyebab tingginya unmet need antara lain akses pelayanan, kurangnya pelayanan $K B$, larangan penggunaan (baik dari suami, keluarga, agama dan masyarakat), takut efek samping, mahalnya biaya, terlalu tua, tidak subur, masalah kesehatan, dan kurangnya informasi tentang alat kontrasepsi. Penelitian deskriptif dengan pendekatan observasional ini bertujuan untuk mengetahui gambaran keinginan unmet need terhadap pelayanan KB di Kota Yogyakarta tahun 2013. Populasi penelitian ini adalah 47.339 PUS dan sampelnya berjumlah 146 PUS yang tergolong unmet need. Hasil penelitian menunjukan sebagian besar responden PUS unmet need tidak ingin menggunakan alat kontrasepsi sampai kapan pun (54,79\%). Tempat mendapatkan pelayanan KB terdekat adalah di Puskesmas (74,83\%). Sebagian besar PUS unmet need menginginkan informasi tentang efek samping KB (70,55\%). Simpulan dari penelitian ini adalah sebagian besar PUS tidak ingin menggunakan alat kontrasepsi sampai kapan pun, tempat mendapatkan pelayanan $K B$ terdekat adalah di Puskesmas, dan sebagian besar PUS unmet neeed menginginkan informasi tentang efek samping $K B$.
\end{abstract}

Kata Kunci: unmeet need, KB, gambaran

Info Artikel:

Artikel dikirim pada 13 September 2013

Artikel diterima pada 3 Oktober 2013

\section{PENDAHULUAN}

Indonesia mengalami masalah dengan kependudukan. Saat ini penduduk di Indonesia berjumlah kurang lebih 237 juta jiwa (BPS, 2010), dengan pertumbuhan penduduk $1,64 \%$ dan Total Fertility Rate (TFR) 2,6\%. Berdasarkan segi kuantitas melalui Indeks Pembangunan Manusia (IPM) kondisi Indonesia sangat memprihatinkan karena dari 117 negara, Indonesia berada diposisi 108. Salah satu cara yang ditempuh untuk menekan laju pertumbuhan penduduk adalah dengan melakukan Program Keluarga Berencana (KB) untuk mengendalikan fertilitas (Handayani, 2010).

Namun demikian program KB ini masih belum terlaksana dengan optimal terbukti dengan terjadinya kenaikan TFR yang disebabkan oleh beberapa faktor diantaranya masih banyak Pasangan Usia Subur (PUS) yang tidak menggunakan alat kontrasepsi (unmet need). Hal itu akan menyebabkan laju pertumbuhan penduduk semakin meningkat. Hal ini merupakan indikator- indikator untuk mengukur keberhasilan pelaksanaan Program Pembangunan Kependudukan dan Keluarga Berencana (Handrina, 2011).

Dalam program KB di Indonesia, jika diperhatikan terjadi peningkatan jumlah PUS yang ingin menunda kehamilan atau tidak menginginkan tambahan anak tetapi tidak menggunakan alat kontrasepsi (Unmet Need KB), yaitu meningkat dari $8,6 \%$ menjadi $9,1 \%$ (Ismail, 2009). Hal ini sangat memprihatinkan karena diharapkan pada akhir tahun 2014 prevalensi unmeet need ini dapat diturunkan menjadi sebesar $5 \%$ (BKKBN, 2012).

Provinsi Daerah Istimewa Yogyakarta (DIY) merupakan salah satu provinsi di Indonesia yang mempunyai unmet need yang tinggi, pada tahun 2012 di Provinsi DIY peserta KB aktif mencapai $73,29 \%$ dari 34.737 PUS, dan untuk unmet need mencapai 13,69\% dari 5.729 PUS dengan rincian: Ingin Anak Tunda (IAT) 5,29\% dari 2.507 PUS, Tidak Ingin Anak Lagi (TIAL) 6,80 dari 3.222 PUS (BKKBN, 2012). 
Beberapa alasan diidentifikasi untuk mengetahui kenapa wanita yang sebenarnya sudah tidak ingin hamil lagi atau ingin menunda anak lebih dari 24 bulan tidak mau menggunakan kontrasepsi. Dikemukakan beberapa alasan kenapa mereka tidak mau menggunakan kontrasepsi seperti alasan karena tidak adanya akses pelayanan, kurangnya pelayanan KB, larangan penggunaan (baik dari suami, keluarga, agama dan masyarakat), takut efek samping, mahalnya biaya, terlalu tua, tidak subur, masalah kesehatan, dan kurangnya informasi tentang alat kontrasepsi (Sumini \& Aryekti, 2009).

Berdasarkan penelitian Handrina (2011) alasan istri yang ingin mengontrol kelahiran tetapi tidak menggunakan alat kontrasepsi (unmet need) disebabkan dua alasan yaitu pertama, Sumber Daya Manusia (SDM) yang masih rendah dengan pola pikir yang tradisional dilatar belakangi oleh faktor keagamaan dan kultur budaya sehingga kesalahan dalam menentukan pilihan pemakaian alat kontrasepsi dapat menimbulkan efek samping terutama gangguan kesehatan bagi perempuan/ istri. Kedua, adanya larangan dari suami. Kedua alasan tersebut berkaitan dengan faktor penyebab yaitu keterjangkauan program KB terkait dengan berkurangnya jumlah penyuluh KB dan kurangnya pengetahuan PUS tentang alat kontrasepsi, serta lemahnya pelaksanaan program KB terkait dengan menentukan pilihan terhadap pemakaian alat kontrasepsi.

\section{BAHAN DAN METODE}

Jenis Penelitian ini adalah penelitian deskriptif. Penelitian deskriptif adalah penelitian yang bertujuan melakukan diskripsi mengenai fenomena yang ditentukan baik berupa faktor resiko maupun efek hasil, fenomena hasil penelitian disajikan secara apa adanya dan peneliti tidak mencoba menganalisa

Tabel .1. Distribusi frekuensi karakteristik responden

\begin{tabular}{lcr}
\hline Karakteristik & Frekuensi & Prosentase (\%) \\
\hline Umur Ibu & & \\
$<20 \quad$ Tahun & 2 & 1,36 \\
$20-35$ Tahun & 59 & 40,51 \\
$>35 \quad$ Tahun & 85 & 58,31 \\
\hline Pendidikan Ibu & & \\
SD/ Tidak Tamat SD & 17 & 11,64 \\
Tamat SMP/Sederajat & 36 & 24,65 \\
Tamat SMA/Lebih Tinggi & 93 & 63,69 \\
\hline Pekerjaan ibu & & \\
Bekerja & 67 & 45,89 \\
Tidak Bekerja & 79 & 54,48 \\
\hline
\end{tabular}

Sumber: Data Primer 2013 bagaimana dan mengapa fenomena tersebut dapat terjadi, sehingga pada penelitian diskriptif tidak perlu ada hipotesis (Ismail, 2012).

Sampel dalam penelitian ini adalah Pasangan Usia Subur (PUS) berumur 15-49 tahun yang tidak menggunakan $\mathrm{KB}$, atau unmet need. Variabel dalam penelitian ini adalah variabel tunggal.

Tabel 2 Distribusi Frekuensi Responden Berdasarkan Waktu rencana penggunaan alat kontrasepsi yang akan digunakan

\begin{tabular}{|c|c|c|}
\hline $\begin{array}{c}\text { Waktu rencana penggu- } \\
\text { naan alat kontrasepsi dan } \\
\text { jenis yang akan digunakan }\end{array}$ & Frekuensi & Persentase \\
\hline $\begin{array}{l}\text { Segera akan memakai dalam } \\
\text { waktu dekat }\end{array}$ & 7 & 4,79 \\
\hline $\begin{array}{l}\text { Keinginan ada, belum tahu } \\
\text { kapan akan KB }\end{array}$ & 49 & 33,56 \\
\hline $\begin{array}{l}\text { Tidak ingin KB sampai kapan } \\
\text { pun }\end{array}$ & 80 & 54,79 \\
\hline Lainnya* & 10 & 6,85 \\
\hline
\end{tabular}

*setelah memiliki anak ke dua, tidak tahu

Sumber: Data Primer 2013

Tabel 3 Distribusi Frekuensi Responden tentang tempat pelayanan KB terdekat

\begin{tabular}{lcc}
\hline $\begin{array}{l}\text { Dimana tempat pelayanan } \\
\text { KB terdekat }\end{array}$ & Frekuensi & Persentase \\
\hline Bidan/ dokter praktek swasta & 35 & 23,97 \\
Puskesmas & 110 & 74,75 \\
Lainnya * & 1 & 0,68 \\
\hline *klinik swasta & \\
Sumber: Data Primer 2013 & \\
\multicolumn{4}{c}{ Tabel 4.Distribusi Frekuensi Responden tentang } \\
\multicolumn{3}{c}{ informasi yang dibutuhkan mengenai alat } \\
\multicolumn{3}{c}{ kontrasepsi } \\
\hline Informasi yang dibutuhkan & Frekuensi & Persentase \\
\hline Jenis alat kontrasepsi & 13 & 8,90 \\
Efek samping & 103 & 70,55 \\
Cara pemakaian & 1 & 0,68 \\
Lainnya* & 29 & 19,86 \\
\hline
\end{tabular}

*tidak memerlukan info

Sumber: Data Primer 2013

\section{HASIL DAN BAHASAN}

Karakteristik subyek responden yang diambil oleh peneliti adalah PUS di RW terpilih di kota Yogyakarta tahun 2013 yang berjumlah 146 responden. Responden tersebut diambil dari data PUS yang didapat dari petugas PPKBD setempat. Adapun karakteristik reponden sebagai berikut: 
Tabel 1 menunjukkan bahwa karateristik PUS berdasarkan umur, PUS dengan umur $>35$ tahun lebih banyak dibandingkan dengan jumlah PUS umur $<20$ tahun. PUS dengan umur $>35$ tahun sebanyak 85 PUS atau $58,31 \%$, sedangakan PUS umur $<20$ tahun sebanyak 2 PUS atau 1,36\%. Berdasarkan tingkat pendidikan PUS dengan pendidikan SMA/ lebih tinggi merupakan jumlah yang paling banyak yaitu 93 PUS atau $63,69 \%$. Hasil penelitian menurut pekerjaan sebagian besar PUS adalah tidak bekerja atau sebagai lbu Rumah Tangga (IRT) sebanyak 79 PUS atau $54,10 \%$, sedangkan PUS yang bekerja sebagai sebanyak 67 PUS atau $45,89 \%$. Waktu rencana penggunaan alat kontrasepsi dikelompokan menjadi 4 kategori.

Berdasarkan tabel. 2 dalam rencana penggunaan alat kotrasepsi diketahui bahwa ibu berkeinginan tidak ingin menggunakan alat kontrasepsi sampai kapan pun lebih banyak yaitu 80 PUS atau 54,79\%, sedangkan kategori segera akan memakai dalam waktu dekat lebih sedikit sebanyak 7 PUS atau 4,79\%.

Berdasarkan tabel.3 menunjukkan bahwa Puskesmas merupakan tempat pelayanan KB terdekat sebanyak 110 PUS atau $74,75 \%$ dibandingkan dengan lain-lainya sebanyak 1 PUS atau $0,68 \%$. Berdasarkan tabel.4 menujukkan bahwa responden yang menginginkan informasi alat kontrasepsi mayoritas menginginkan info tentang efek sampingsebanyak 103 PUS atau $70,55 \%$, sedangkan yang terendah hanya menginginkan informasitentang cara pemakaian alat kontrasepsi sebanyak 1 PUS atau $0,68 \%$.

\section{Pembahasan}

Unmet need didefinisikan sebagai kelompok wanita yang sebenarnya sudah tidak ingin memiliki anak lagi atau ingin menjarangkan kehamilanya sampai dengan 24 bulan atau lebih namun tidak menggunakan alat kontrasepsi untuk mencegah kehamilanya.Kelompok unmet need merupakan sasaran yang perlu menjadi perhatian dalam pelayanan program KB (Julian, 2009).
Berdasarkan hasil penelitian ini dapat diketahui bahwa total dari jumlah responden yang berkeinginan tidak menggunakan alat kontrasepsi sebanyak 146 PUS yang yang masuk dalam karakteristik unmet need.

\section{SIMPULAN DAN SARAN}

Dari penelitian ini dapat disimpulkan bahwa Prevalensi PUS unmet need yang tidak berkeinginan menggunakan alat kontrasepsi sampai kapan pun sebanyak (54,79\%), Sebagian besar PUS (74,75\%) mendapatkan alat kontrasepsi terdekat di Puskesmas, Sebagian besar responden unmet need $(70,55 \%)$ menginginkan informasi tentang efek samping dari alat kontrasepsi.

\section{RUJUKAN}

1. BKKBN. 2012. Data Laporan Bulanan Kantor KB Kota Yogyakarta. BKKBN : Yogyakarta

2. BKKBN, 2012. Jawa Tengah. 2012. Strategi Pencapaian Target Pelayanan KB dalam Pelatihan Insersi IUD dan Implan bagi Dokter dan Bidan diwilayah Binaan Balai Diklat KKB Pati.

3. dalam BPS, 2010. Data Penduduk Indonesia menurut Provinsi tahun 1971, 1980, 1990, 1995, 2000 dan 2010. dalamhttp://bps.go.id/ tab_sub/view.php?kat=1\&tabel=1\&daftar=1\&id_ subyek $=12 \&$ notab $=1>$ diakses tanggal $1 \overline{6}$ September 2013 jam. 21.00 wib

4. Handayani, Sri. 2010. Pelayanan Keluarga Berencana. Yogyakarta : Pustaka Rihama

5. Handrina, Emi. 2011. Faktor Penyebab Unmet Need Suatu Studi di Kelurahan Kayu Kubu Kecamatan Guguk Panjang Kota Bukittinggi. Tesis. Sumatera Barat: Universitas Andalas

6. Ismail, Sofyan. 2012. Metodologi Penelitian Klinis. Jakarta : Binarupa Aksara.

7. Sumini, \& Aryekti, Kanti. 2009. Survei Demografi dan Kesehatan Indonesia 2007 Provinsi di Yogyakarta. Jakarta: KB dan Kesehatan reproduksi, BKKBN. 